\title{
Correction to: lonomic variation in leaves of 819 plant species growing in the botanical garden of Hokkaido University, Japan
}

\author{
Toshihiro Watanabe $^{1}$ [D $\cdot$ Takayuki Azuma ${ }^{2}$
}

Published online: 19 February 2021

(c) The Botanical Society of Japan 2021

\section{Correction to: Journal of Plant Research https://doi.org/10.1007/s10265-021-01254-y}

In the original publication of the article, units were published incorrectly in Table 2, 3 and 4.

In table 2, the unit below " $\mathrm{K}$ " and "Fe" was published incorrectly as " $\left(\mathrm{Mg} \mathrm{g}^{-1}\right)$ ". The correct unit is " $\left(\mathrm{mg} \mathrm{g}^{-1}\right)$ " and " $\left(\mu \mathrm{g} \mathrm{g}^{-1}\right)$ " respectively.

In tables 3 and 4 , the unit "( $\mu \mathrm{g}$ g dry weight $\left.{ }^{-1}\right)$ " published below "Mo" was redundant.

The original article has been updated.

The original article can be found online at https://doi.org/10.1007/ s10265-021-01254-y.

Toshihiro Watanabe

nabe@chem.agr.hokudai.ac.jp

1 Research Faculty of Agriculture, Hokkaido University, Kita-9, Nishi-9, Kitaku, Sapporo 0608589, Japan

2 Field Science Center for Northern Biosphere, Botanic Garden, Hokkaido University, Kita-3, Nishi-8, Chuoku, Sapporo 0600003, Japan
Publisher's Note Springer Nature remains neutral with regard to jurisdictional claims in published maps and institutional affiliations. 